\title{
Defining the correlation between immune-checkpoint inhibitors-related adverse events and clinical outcomes: a narrative review
}

\author{
Omar Abdihamid ${ }^{1}$, Abeid Omar ${ }^{2}$ and Tibera Rugambwa ${ }^{3}$ \\ ${ }^{1}$ Department of Oncology, Xiangya Hospital, Central South University, Changsha, Hunan 410008, People's Republic of China \\ ${ }^{2}$ Department of Clinical Oncology and Nuclear Medicine, Faculty of Medicine, Alexandria University, Champlion Street, Alazarita, Alexandria 21131, Egypt \\ ${ }^{3}$ Department of Internal Medicine, Mbeya Zonal Referral Hospital, Mbeya 419, Tanzania
}

\section{Abstract}

Immune checkpoint inhibitors (ICls) have increased modern anticancer armamentarium portfolios, with 15\%-60\% of cancer patients deriving clinical benefit while others progress, including some occurrences of accelerated progressions. ICls have also introduced a new pattern of immune-related adverse events (irAEs). Recently, a mechanistic link was proposed in which patients who develop ICls-related irAEs derive a survival benefit compared to those who do not, suggesting an overlap between toxicities and the treatment efficacy. Identifying predictive biomarkers to optimally identify patients who will benefit from ICls is a contemporary research area in Oncology. However, the data remains sparse, with only several smaller studies showing a plausible direct proportionality of a therapeutic effect across tumours. In contrast, the overall survival and progression-free survival rate depend on the tumour type, degree of toxicities, duration of exposure, affected system/organs and inherent patient characteristics. Furthermore, the occurrence of irAEs appears to be more associated with a clinical benefit from programmed death 1 and programmed death-ligand 1 inhibitors than anti-cytotoxic T-lymphocyte-associated antigen 4. Several questions remain unanswered, including the association between survival benefit and specific type of organ system toxicities, toxicity grade, if the benefit is entirely due to immortal-time biases (ITBs), presence of patients confounding comorbidities like autoimmune diseases, and finally, immune heterogeneities. Considering ITB represents a key element in interpreting these studies since patients with precipitated death or with an earlier disease progresses rarely develop irAEs; in fact, such patients have not stayed in the study long enough to experience such irAEs. Conversely, patients that stayed in the study for a longer period have a higher risk of developing irAEs. Landmark analysis is key in these studies if a real association is to be found. Overall response and disease control rates are mainly higher in those who develop irAEs due to immune activation. So, this review aims to summarise the evidence from key studies that addressed this important clinical question.

Keywords: immune checkpoint inhibitors, adverse events, anti-PD-1, anti-PD-L1, anti-CTLA-4, efficacy, survival, correlation
Correspondence to: Omar Abdihamid Email: omaryhamidy@gmail.com

ecancer 2021, 15:1314

https://doi.org/10.3332/ecancer.2021.1314

Published: 02/11/2021

Received: 07/03/2021

Publication costs for this article were supported by ecancer (UK Charity number 1176307).

Copyright: (C) the authors; licensee ecancermedicalscience. This is an Open Access article distributed under the terms of the Creative Commons Attribution License (http:// creativecommons.org/licenses/by/4.0), which permits unrestricted use, distribution, and reproduction in any medium, provided the original work is properly cited. 


\section{Introduction}

Our immune system remains our first line of defence in any disease, including cancer. Harnessing it by enhanced immune activation while maintaining an equilibrium of self-tolerance is what modern science continues to achieve.

Cancer cells harbour mechanisms to evade immune surveillance by hijacking the physiological immune negative regulators, posturing as a 'self' cell, and eventually evading immune distraction. Immune checkpoint inhibitors (ICls) are a class of anticancer drugs known as monoclonal antibodies that target receptors like anti-programmed death 1 (anti-PD-1), anti-programmed death-ligand 1 (anti-PDL-1) and the anti-cytotoxic T-lymphocyte-associated antigen 4 (anti-CTLA-4). By inhibiting these innate negative T-cell regulators, the immune system is activated, and its ability to recognise and kill tumour cells is enhanced [1-3]

Immunotherapy is currently considered the 'fifth pillar' of cancer treatment, joining the ranks of chemotherapy, radiotherapy, surgery and targeted therapy. Over the years, several ICl agents have been approved, improving the overall survival (OS) of many cancer patients (Table 1). Amongst the approved ICl agents, anti-PD1 agents have the largest indication across several tumours, including metastatic non-small cell lung cancer (NSCLC) [4], advanced head and neck cancer (HNC) [5], advanced melanoma [6], genitourinary tumours and others [7, 8].

Randomised clinical trials in immuno-oncology include the Keynote 045 trial [9], which showed prolonged OS and preservation of good quality of life (QoL) scores in patients with urothelial cancers (UCs).

The Checkmate 141 trial [5] looked at Nivolumab as a first-line therapy in patients with relapsed or metastatic HNC, and it showed an improvement in progression-free survival (PFS) and QoL.

The Checkmate 214 phase 3 trial [10] looked at renal carcinoma patients receiving either double ICl agents or sunitinib and showed a similar positive outcome in both OS and improved QoL scores in the $\mathrm{ICI}$ group.

Table1. List of approved ICls.

\begin{tabular}{|c|c|c|c|c|}
\hline $\begin{array}{l}\text { International } \\
\text { nonproprietary name }\end{array}$ & Type & Target & FDA or CNMPA indications & Year of approval \\
\hline Ipilimumab & $\operatorname{lgG1} \mathrm{mAb}$ & CTLA-4 & RCC, melanoma, lung cancer & FDA-2011 \\
\hline Pembrolizumab & $\operatorname{lgGa} 4 \mathrm{mAb}$ & PD-1 & $\begin{array}{l}\text { Melanoma, NSCLC and SCLC, SCCHN, cHL, primary large B-cell } \\
\text { lymphoma, UC, GC and breast cancer }\end{array}$ & FDA-2014 \\
\hline Nivolumab & $\operatorname{lgG} 4 \mathrm{mAb}$ & PD-1 & $\begin{array}{l}\text { Metastatic NSCLC, UC, metastatic melanoma, advanced RCC, } \\
\text { SCLC, SCCHN, HCC, metastatic CRC and cHL }\end{array}$ & FDA-2014 \\
\hline $\begin{array}{l}\text { Ipilimumab \& Nivolumab } \\
\text { combination }\end{array}$ & $\lg G 1+\lg G 4 m A b$ & CTLA-4 \& PD-1 & Melanoma, RCC, NSCLC and CRC & FDA-2015 \\
\hline Atezolizumab & $\operatorname{lgG1} \mathrm{mAb}$ & PD-L1 & NSCLC, UC, breast cancer, melanoma, RCC, CRC and SCCHN & FDA-2016 \\
\hline Avelumab & $\operatorname{lgG1} \mathrm{mAb}$ & PD-L1 & Merkel-cell carcinoma, RCC and NSCLC & FDA-2017 \\
\hline Durvalumab & $\operatorname{lgG1} \mathrm{mAb}$ & PD-L1 & UC, NSCLC and SCLC & FDA-2017 \\
\hline Cemiplimab & $\operatorname{lgG1} \mathrm{mAb}$ & PD-1 & Metastatic cutaneous squamous cell carcinoma and myeloma & FDA-2018 \\
\hline Toripalimab & $\operatorname{lgG} 4 \mathrm{mAb}$ & PD-1 & Locally advanced or metastatic melanoma & CNMPA-2018 \\
\hline Sintilimab & $\operatorname{lgG} 4 \mathrm{mAb}$ & PD-1 & Refractory $\mathrm{CHL}, \mathrm{HCC}$ and NSCLC & CNMPA-2018 \\
\hline Camrelizumab & $\operatorname{lgG} 4 / \mathrm{k}$ mAb & PD-1 & $\begin{array}{l}\text { cHL, metastatic HCC, metastatic esophageal cancer and advanced } \\
\text { NSCLC }\end{array}$ & CNMPA-2019 \\
\hline Tislelizumab & $\operatorname{lgG} 4 \mathrm{mAb}$ & PD-1 & Refractory $\mathrm{cHL}$ and UC & CNMPA-2019 \\
\hline
\end{tabular}

CRC, Colorectal cancer; cHL, Classic Hodgkin lymphoma; HCC, Hepatocellular carcinoma; RCC, Renal cell carcinoma; SCCHN, Squamous cell carcinoma of the head and neck; NSCLC, Non-small cell lung cancer; SCLC, Small cell lung cancer; UC, Urothelial carcinoma; FDA: Food and Drug Administration; CNMPA, Chinese national medical product administration 
While there is a well-documented clinical benefit from ICls, the activated immune system causes several off-target and bystander effects to normal tissues, leading to the so-called immune-related adverse events (irAEs) [11]. The similarities between antigens presented on normal tissues and tumour cells are the leading hypotheses for developing these adverse events [12]. Similarly, the aetiology of irAEs is akin to those that promote the anti-tumour effect and mainly involves the expansion of the T cell repertoire. Also, ICls can affect clonal B cell responses, thus inducing autoantibody production [13].

Some irAEs can be subtle and tolerable, while others are rare but life-threatening. irAEs can result in an array of systemic, multi-organ inflammations like liver, thyroid, pituitary, colon and lungs [14].

Studies show that ICls have lower nausea, vomiting, anorexia, fatigue, diarrhoea, neuropathy, haematologic toxicities and treatment discontinuation rate than conventional chemotherapy. Conversely, the signature irAEs like skin rash, pruritus, colitis, pneumonitis, transaminitis and endocrine toxicities are more common with ICls than chemotherapy. Lastly, ICls are overall better tolerated than chemotherapy [15].

Although most irAEs are identified during pre-clinical development, the spectrum, timing and outcomes were only recently investigated through real-world, large-scale pharmacovigilance analyses like the spontaneous reporting systems that looked at the real-time monitoring of these drugs' safety profiles [16]. The term 'immunovigilance' and disproportionality analyses (DAs) have also been proposed. DAs are now the most common epidemiological approach for postmarketing safety assessment and documentation in many ICl agents [17].

There is growing evidence suggesting a potential association between irAEs and clinical benefit in some cancer types [18], and in fact, several reports have shown that irAEs are not only associated with ICl efficacy but also precede response [19-21]. However, a possible bias exists in which responders benefit from long-term ICl therapy and are therefore exposed to a higher risk of developing irAEs throughout time [22].

The main bias in the association between irAEs and clinical outcomes is the immortal time bias (ITB); defined as bias arising from methodologically wrong analyses of time-dependent events in survival analyses [23].

Considering ITB represents a key element in interpreting these studies since patients with precipitated death or with an earlier disease progresses rarely develop irAEs; in fact, such patients have not stayed in the study long enough to experience such irAEs. Conversely, patients that stayed in the study for a longer period have a higher risk of developing irAEs.

Furthermore, despite several studies providing interesting data, this association should be interpreted with caution because the majority of these studies did not report or adjusted for the effect of ITB in their survival analyses [24].

Landmark analysis is the recommended solution to such biases since it splits the follow-up period at a given time point. Patients groups are then defined by time-dependent development of irAEs, such as before and after the landmark, with clinical outcomes only considered if occurring after the landmark [23].

\section{The spectrum of irAEs}

Cutaneous toxicities are the most common irAEs resulting from ICl therapy and often present as a distinct pruritic maculopapular rash, commonly seen on the trunk and the limbs, exacerbated by underlying psoriasis. A grade 3 or 4 (G3, G4) with a bullous appearance akin to Stevens-Johnson syndrome is seen in severe cases, especially in patients with underlying autoimmune disease [21, 25, 26].

Gastrointestinal symptoms such as abdominal pain and diarrhoea secondary to colitis are classic ipilimumab-related irAEs that manifest as loose stool, abdominal pain, haematochezia and fever. Interleukin-6 productions can cause an attack on enterocytes by the activated T-cells, and if left unrecognised, it can lead to intestinal perforation. Hepatic involvement usually manifests as asymptomatic hepatitis with transaminitis. Acute pancreatitis can present with abdominal or back pain with nausea and vomiting or can be more severe by causing autoimmune destruction of the pancreatic islet cells. Such patients are usually asymptomatic until they present with full-blown diabetic ketoacidosis [27].

Endocrine irAEs can be insidious in onset and usually present with hypophysitis with diminished downstream thyroid and adrenal steroid production, or occasionally with severe headache as the pituitary becomes acutely inflamed [28].

Renal toxicity is typically detected as high serum creatinine levels, which usually prompt the discontinuation of ICls. Pneumonitis classically presents with a dry cough, dyspnoea with or without hypoxaemia. Ocular toxicities can present with visual symptoms such as blurry vision and retinitis or even proptosis resulting from the inflammation of extraocular muscles. 


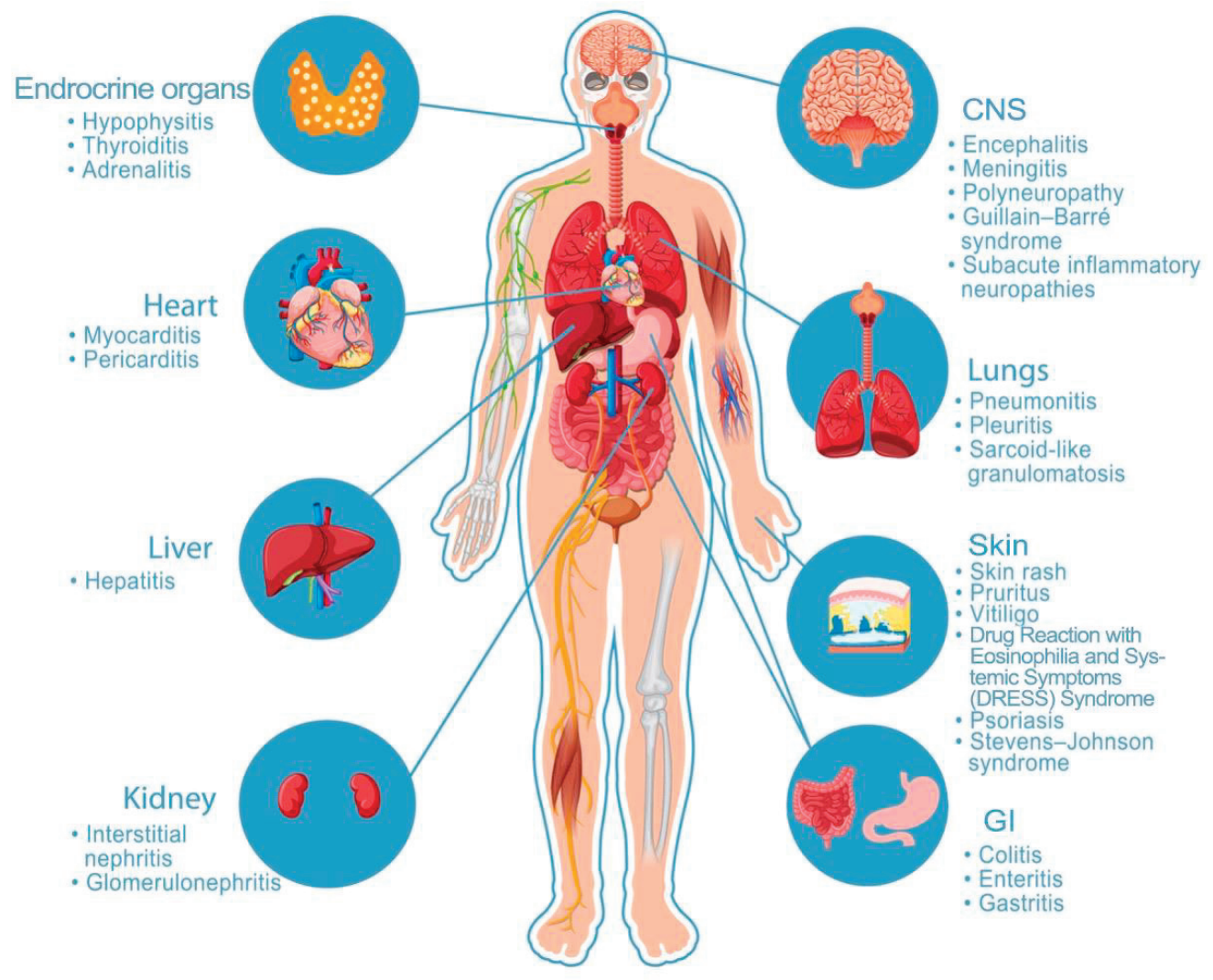

Figure 1. Immunotherapy-related anatomic based irAEs. Anatomic based ICls related adverse events.

Neurologic toxicities are fatal irAEs and usually involve the brain, peripheral nervous system, leptomeninges or even autoimmune destruction of the autonomic nervous system. The antiviral response resulting from the use of $\mathrm{ICl}$ agents can result in encephalitis.

The endogenous expression of CTLA-4 on the pituitary can also lead to hypophysitis. Musculoskeletal toxicities usually include myalgias, arthralgias with elevated muscle enzymes signifying significant muscle destruction [26, 27].

Cardiotoxicity, which can present as fulminant myocarditis, is one of the rare but catastrophic irAEs. Myocytes express shared antigens with the tumours, which can lead to autoimmune distraction. It usually mimics heart failure symptoms and can also present with arrhythmias and conduction abnormalities. These patients are usually managed with joint help from cardiologists, even as the cardio-oncology sub-speciality continues to become popular [29,30]. A pictorial view of the organ system-based irAEs is shown in Figure 1.

\section{Incidence}

Data emerging from randomized clinical trials (RCTs) shows that the frequency and the incidence of irAEs usually depend on the ICI agent used, duration of exposure, dose and patient's risk factors profile. On the other hand, the kinetics and the timing of irAEs are dependent on the affected organ system [21]. A higher incidence of G1 to G5 toxicities is usually common in anti-CTLA-4, moderate with PD-1 class and lower in PD-L1 agents. Intriguingly, different tumour types had different tissue type inflammation resulting from ICI use. For example, colitis was mostly found in melanoma patients [31], whereas pneumonitis was more common in lung cancer patients [32]. 
In a review of 125 RCTs, 75 different irAEs, including fatigue (18.3\%), diarrhoea (9.5\%) and pruritus (10.6\%), have been reported. Also, two in every three patients experienced at least one G3 toxicity, citing the true incidence and impact of irAEs [33]. A systematic review of 35 immunotherapy RCTs reported the true incidence of IrAEs as follows: $\mathrm{PD}$ (L)-1 inhibitors (14\%), ICl combinations (55\%), ICl-chemotherapy combo (46\%) and CTLA-4 inhibitors (34\%). Grade 3 or more IrAEs were common, especially in ICl combination therapies. Thirty-two (91\%) RCTs were performed in the metastatic or locally advanced stage, whereas only three (9\%) trials were conducted on neoadjuvant or adjuvant settings [34].

$\mathrm{ICl}$ monotherapy versus combined $\mathrm{ICl}$ is associated with fewer irAEs. A meta-analysis showed that the $\mathrm{ICl}$ combo significantly increased the development of any-grade irAEs, including colitis, pneumonitis, hypothyroidism, hypophysitis, amongst others [35]. Similarly, an analysis of 18 studies with 2,767 patients across cancer types showed that combination ICI therapy was associated with a higher risk of all-grade irAEs (Response rate (RR): 1.07; 95\% confidence interval (CI): 1.03-1.11) and markedly greater risk of G3 or higher adverse events (RR: 2.21; $95 \%$ Cl: 1.57-3.10) compared to monotherapy ICI [36].

A detailed study that queried irAEs from the World Health Organization databases (VigiBase) found 613 ICl-related fatal toxic events from 2009 to 2018. Amongst these fatalities, 193 deaths from anti-CTLA-4 agents, mostly from colitis (135 cases), while fatalities from pneumonitis (333), hepatitis (115) and neurotoxic effects (50) were associated with anti-PD-1/PD-L1 use. Similarly, deaths from ICI combos were frequently from colitis (25 cases) and myocarditis (32 cases) [30].

Retreatment with $\mathrm{ICl}$ after a clinically significant previous irAE is common. A multicentre retrospective study of 499 patients identified ICI patients with renal cell carcinoma (RCC) in which 80 patients developed severe irAEs warranting treatment cessation, 36 of whom were able to be restarted on an $\mathrm{ICl}$ agent and 44 permanently discontinued. Time to initial irAE was similar between the two groups (2.8 versus 2.7 months; $p=0.59$ ) [37].

Similarly, in a retrospective study of 80 patients with metastatic melanoma who received a combined CTLA-4 and a PD-1 inhibitor, patients who developed irAEs warranting treatment discontinuation were later rechallenged with a single-agent PD-1 inhibitor. The rates of toxicities amongst patients who resumed single-agent anti-PD-1 were notably lower (for example, G3/4 colitis declined to 3\%, and G3/4 hepatitis declined to 7\%) [38].

A review of $38 \mathrm{RCTs}$ comprising 7,551 patients on $\mathrm{ICl}$ therapy evaluated the incidence of endocrine irAEs and found a higher incidence of hypo and hyperthyroidism, especially in patients receiving combined ICI therapy (OR: 3.81; 95\% Cl: 2.10-6.91; $p<0.001)$. Moreover, PD-1 inhibitors, in particular, were associated with hypothyroidism as compared to CTLA-4 inhibitors (odds ratio (OR): 1.89; $95 \%$ Cl: 1.17-3.05; $p=0.03$ ) [39].

Interestingly, it is also common to diagnose irAEs even after the discontinuation of $\mathrm{ICl}$ agents. In a retrospective review of 64 patients with metastatic melanoma treated with Nivolumab plus Ipilimumab, 31 patients experienced early toxicity warranting discontinuation of treatment, and 4 of these (13\%) further developed a significant irAEs 4 months after treatment cessation. Therefore, both clinicians and patients should be aware of this trend [40].

Therefore, it is crucial to anticipate the occurrence of irAEs and educate patients on the risks. Weber et al [41] conducted a pooled safety data analysis from four studies consisting of 576 patients with irAEs of any grade. They found most of these events occurred within the first 4 months of therapy, and skin was the commonly involved site, followed by the gastrointestinal and the endocrine system. The authors also noted some toxicities occurred as late as day 60.

On the general safety profiles of $\mathrm{ICl}$ agents, a head-to-head comparison of 36 phase 1 and phase 2 clinical trials that enrolled 15,370 patients found that the safety ranking of ICls as follows: Atezolizumab (pooled incidence 66.4\%, probability 76\%), Nivolumab (71.8\%, 56\%), Pembrolizumab (75.1\%, 55\%), Ipilimumab (86.8\%, 55\%) and Tremelimumab (not applicable (NA), 54\%). Atezolizumab had the overall best safety profile, while Nivolumab had the best safety data in lung cancer [42].

Lastly, tumour and class-specific irAEs are an unresolved and controversial topic. While anti-CTLA-4 agents are believed to be more toxic than anti-PD-1/PD-L1 drugs, a definitive comparison is lacking due to their different therapeutic uses. However, others have speculated that anti-PD-L1 drugs could be less toxic than anti-PD-1 agents due to the preservation of PD-L2 signalling [43]. 


\section{Tumour-specific irAEs and clinical outcomes}

A mechanistic link was proposed by the investigators of a prospective cohort study in which 73 NSCLC patients treated ICI showed that there was shared cancer and tissue antigens and T cell infiltration in both the lung tumour and the skin, suggesting an overlap between the toxicities and the efficacy [44].

In a similar study of 559 NSCLC patients, the incidence of irAEs was $41.3 \%$ (231 patients), and 50 patients (8.9\%) developed grade 3 or 4 events. Using a landmark analysis at 6 weeks, the authors confirmed that irAEs of any grade were an independent predictor of higher overall response rate (ORR), longer OS and more prolonged PFS [45].

A study of 99 Phase III oncology RCTs found both toxicity and efficacy were higher amongst the treatment arm than the control (all grade toxicities were 3.5 times higher in the treatment than the control arm, $p<0.001$; mean OS of 18.6 versus 16.9 months; $p<0.001$; mean PFS of 9.1 versus 7.1 months; $p<0.001$, respectively). Notably, the authors concluded that, across the RCTs, irAEs were strongly associated with higher PFS in ICl patients versus controls $(p<0.001)$, but not OS $(p=0.44)$ [46].

A systematic review looking at the emerging evidence on the association between IrAEs and clinical outcomes highlighted the existence of a plausible direct proportionality of a therapeutic effect across $\mathrm{ICl}$ agents and solid tumours [47].

A meta-analysis of 30 studies that enrolled 4,324 patients who received ICI, those who developed irAEs had a reduced risk of death (hazard ratio $(\mathrm{HR})=0.49 ; 95 \% \mathrm{Cl}: 0.38-0.62 ; p<0.001)$, and the development of irAEs conferred a reduced risk of progression $(\mathrm{HR}=0.51 ; 95 \% \mathrm{Cl}$ : $0.42-0.64 ; p<0.001)$. The authors believe these findings could be related to strong immune activation [48].

In a large safety and efficacy data analysis of 1,783 patients receiving Avelumab from the Merkel 200 trials and the JAVELIN Solid Tumor, $16 \%$ (295 patients) developed irAEs. A time-dependent Cox model analysis found a reduced risk of death in patients with irAEs than those without (HR: 0.71; 95\% Cl: 0.59-0.85) [49].

In a multicentre pooled analysis of 531 patients with metastatic NSCLC treated with Nivolumab as a second line therapy, $33.0 \%$ (173 patients) developed irAEs and had a significantly longer OS (14.9 versus 7.4 months; HR: 0.66; 95\% Cl: 0.52-0.82); $p<0.001$ as compared to patients with no irAEs and a PFS (6.1 versus 3.1 months; HR: 0.68; 95\% Cl: 0.55-0.85); $p=0.001$. The authors also noticed a negative impact on patients' prognosis resulting from treatment discontinuation due to irAEs; median OS (3.6 versus 17.6 months; HR: 2.61 ; $95 \%$ Cl: $1.61-4.21) ; p<0.001$, PFS (2.3 versus 6.6 months; HR: 1.74; 95\% Cl: 1.06-2.80); $p=0.02$ [50].

$\mathrm{ICI}$ has revolutionised the treatment landscape and improved survival in metastatic melanoma. The onset of specific irAEs like vitiligo has been investigated in different studies. In a multivariate analysis, irAEs were associated with improved PFS (HR: 0.47; 95\% Cl: 0.26-0.86); $p$ $=0.016$, and a better OS; (HR: $0.39 ; 95 \% \mathrm{Cl}$ : 0.18-0.81); $p=0.007$. Vitiligo was associated with a moderate improvement of OS compared with other irAEs $(p=0.061)[51,52]$

In a similar melanoma study in the Chinese population of 93 patients who received ICI therapy, frequent irAEs were pruritus, vitiligo, rash and fatigue. The median onset of irAEs was 6.1 weeks. Both disease control rates (DCRs) and ORR were higher in the irAEs group than those without ( $p=0.004$ and $p=0.003$, respectively) [53].

Furthermore, apart from the established impact of cutaneous irAEs on OS of melanoma patients, gastrointestinal irAEs, especially diarrhoea, which usually limits ICI treatment, was paradoxically associated with improved OS and PFS in metastatic melanoma patients (HR 0.56; 95\% $\mathrm{Cl}: 0.41-0.76 ; p<0.01)[31]$.

Thyroid irAEs induced by Nivolumab in a cohort of 200 Japanese patients found that patients with overt thyroid uptake as depicted by fluorodeoxyglucose-positron emission tomography (FDG-PET) had a high incidence of irAEs but with an OS benefit (16.1 versus 13.6 months; HR: 0.61; 95\% Cl: 0.39-0.93) [54].

A retrospective pan-cancer analysis study, albeit from a single centre looking at 212 patients with either metastatic or recurrent RCC, melanoma, NSCLC and gastric cancer (GC) who received ICI therapy, showed that 108 patients had solitary organ irAEs, while 42 developed multiple site irAEs. Generally, the OS was longer in patients with any category of irAEs than those without irAEs (28.1 versus 12.7 months; HR: 0.49; 95\% Cl: 0.33-0.73; $p=0.0004)$. Also, patients with multiple site irAEs had a markedly longer OS than those with single site irAE (42.3 versus 18.8 months; HR: 0.473; 95\% Cl: 0.346-0.647; $p<0.0001$ ) [55]. 
In a similar anatomical based irAEs study, a meta-analysis that included 4,971 patients from 30 studies found both OS and PFS benefits from $\mathrm{ICl}$ therapy as compared to those without irAEs (PFS: HR: 0.52; 95\% Cl: 0.44-0.61; $p<0.001 ; 0 S: \mathrm{HR}: 0.54 ; 95 \% \mathrm{Cl}: 0.45-0.65 ; p<0.001$ ). Further subgroup analyses found that dermatological irAEs (OS: HR: 0.45; 95\% Cl: 0.35-0.59; $p<0.001)$, endocrine irAEs (OS: HR: 0.52; 95\% Cl: $0.44-0.62 ; p<0.001$ ) and low-grade irAEs (OS: HR: 0.57; 95\% Cl: 0.43-0.75; $p<0.001$ ) equally yielded same results [56].

Although cutaneous irAEs like vitiligo confers a clinical efficacy in melanoma, the benefit in other cancers remains unknown. A retrospective 6-week landmark analysis of 155 NSCLC patients who received either Pembrolizumab or Nivolumab monotherapy showed that the median time to rash onset was 6.4 weeks. The ORR was higher in patients with cutaneous reactions (57\% versus $19 \%$; $p<0.001)$ and a median PFS of 12.9 versus 3.5 months. Multivariate analysis identified rheumatoid factor positivity as an independent predictor of cutaneous irAEs [57].

A similar retrospective analysis of 40 NSCLC patients on Nivolumab found a better RR in those with skin toxicity (42\%) than those without (7\%) [12].

Rheumatological irAEs are not commonly reported as signature irAEs in patients receiving immunotherapy. Kostine et al [58] looked at the impact of rheumatologic side effects in all ICl agents and irAEs sites on ORR. The ORR was higher in patients with rheumatologic side effects (85.7\% versus $35.3 \% ; p<0.0001$ ) compared to their counterparts [58].

The association of irAEs and clinical outcomes in NSCLC patients with existing brain metastasis who received ICls is also not well studied. A small retrospective review of 63 patients found that any grade irAEs were associated with longer OS (21 versus 10 months; $p=0.004)$ and delayed treatment failure (14 versus 5 months; $p=0.001$ ), especially in patients with high PD-L1 expression [59].

ICl-related pneumonitis (ICIP) is a common and potentially life-threatening irAE in NSCLC patients. A real-world cohort study looked at the risks of developing ICIP in NSCLC patients who received prior radiotherapy and are currently on ICI therapy. Expectedly, the study found prior radiotherapy was not only associated with a higher risk of ICIP but was an independent prognostic factor for low survival in NSCLC patients [60].

Immunotherapy data in GC is not as robust, and the survival benefit from ICI has been modest. Nonetheless, a multicentre study of 76 GC patients who received Food and Drug Administration (FDA) approved ICI agents showed irAEs were associated with a better outcome in PFS and OS (PFS: 3.9 months versus not reached; HR: 0.13; 95\% Cl: 0.05-0.3; $p$ < 0.001; OS: 7.4 months versus not reached; HR: 0.11 ; $95 \% \mathrm{Cl}$ : $0.03-0.36 ; p<0.001[61]$.

On the other hand, UCs have received more ICI agents FDA approvals than many other cancers. The occurrence and the spectrum of IrAEs corresponded with higher efficacy, higher ORR (52\% versus $16 \% ; p<0.01$ ), better PFS (11.0 versus 3.6 months; $p<0.01$ ) and OS (13.1 versus median not reached) as compared to those without IrAEs [62]. In another study of UC patients, those who developed irAEs had an ORR of 33.0\% versus $8 \%$, and at 15 months median follow-up, all the patients with irAEs were still alive, compared to only 38\% of their counterparts [63].

Metastatic RCC patients receiving ICl therapy who developed irAEs had a median OS of 35.9 versus 26.5 months; $\mathrm{HR}$ : 0.376 ; $95 \% \mathrm{Cl}$ : 0.179-0.792; $p=0.010$ [64]. Similarly, Ishihara et al [65] reported a PFS (13.1 versus 4.87 months; HR: 0.25; 95\% Cl: 0.11-0.56) in RCC patients with any grade of irAEs versus those without.

Immunotherapy is also approved for metastatic HNC [66]. A similar benefit on RR, PFS and OS has been reported in patients receiving $\mathrm{ICl}$ agents who developed irAEs [67]. A single-centre study of 89 patients with relapsed or metastatic squamous cell HNC treated with Nivolumab showed that the median OS was significantly longer in patients with irAEs than those without (17.9 versus 6.3 months; log-rank $p=0.004)$. The authors also reported a median PFS (10.2 versus 2.8 months) in those with versus without irAEs [68].

Although not commonly reported, ICI therapy-related pyrexia was associated with a longer PFS in one study (6.4 versus 2.1 months; $p=0.26$ ) in patients with advanced NSCLC. Similarly, a better ORR trend was also seen in those who developed pyrexia (65\% versus $35 \% ; p=0.29)[69]$.

Apart from the common $\mathrm{ICl}$ monoclonal antibody-based drugs, monocyte-derived vaccines or dendritic cells (DC) loaded with tumourassociated antigens gp100 are also part of the immuno-oncology armamentarium. In a retrospective analysis of advanced melanoma patients vaccinated with DC vaccines, $84 \%$ of the patients developed irAEs, mostly injection site reactions (50\%) and flu-like symptoms (67\%), and both correlated with immunologic and clinical outcomes (both $p<0.001$ ) [70]. 
Further compounding the association between the occurrence of irAEs and efficacy conundrum is the common use of steroids to counteract adverse events in patients receiving ICl therapy. In a study by Riudavets et al [71], Prednisone has been found to significantly affect median OS in patients receiving more than $10 \mathrm{mg}$ a day than those with less than $10 \mathrm{mg}$ (6 versus 15.9 months; $p<0.001$ ) [71].

Conversely, a retrospective analysis of 157 patients with different tumour types assessed the effects of irAEs and steroid use on PFS. Forty-five of these patients developed irAEs, in which 21 patients received steroids. Development of irAEs and steroid use was found to improve PFS by Kaplan-Meier estimate. Also, multivariate regression showed that irAEs improved PFS (HR: $0.33 ; p<0.001$ ) and persisted even with steroid use (HR: 0.38; $p=0.03)$. Indeed, steroids' role and their effect on ICl therapy remain an evolving space with many discrepancies [72].

While there are no extensive RCTs data that discredit the association of irAEs with good clinical outcomes, a landmark analysis of a retrospective review of only 97 patients showed no difference in OS at 3 months in patients on single-agent ICl, even though the incidence of irAEs was associated with an OS (24.3 versus 5.3 months; HR: $2.75 ; 95 \% \mathrm{Cl}: 1.54-4.92 ; p<0.001)$ for those with and without irAEs, respectively [32].

A systemic review of 16 studies reported that specific irAEs like mucositis, pneumonitis, myalgias and thyroid disorders are not statistically correlated with OS [73]. Moreover, potential bias and confounding factors were identified in the assumption that patients who develop irAEs remain on treatment longer and hence have a better outcome than their counterparts, and as such, could only be attributed to guaranteetime bias $[74,75]$.

Amongst the coterie of the larger studies looking at this association, the consensus is that there is potentially an association between the development of irAEs and OS, ORR and PFS in patients treated with ICls, irrespective of disease site, type of ICl and irAEs spectrum. Conversely, higher degrees of toxicity grade (G3 or higher) led to a better ORR only but a worse OS [52]. More similar studies that investigated the association of irAEs and patients' outcomes are shown in Table 2.

Table 2. Studies comparing the association between irAEs and clinical outcomes.

\begin{tabular}{|c|c|c|c|c|c|}
\hline Study & Cancer type & $\begin{array}{l}\text { Sample } \\
\text { size }\end{array}$ & $\mathrm{ICl}$ agent & $\begin{array}{l}\text { Survival outcomes in patients with and } \\
\text { without irAEs (OS, PFS) }\end{array}$ & $\begin{array}{l}\text { RR in patients with versus } \\
\text { without irAEs }\end{array}$ \\
\hline Weber et al [41] & Melanoma & 576 & Nivolumab & PFS (no difference; HR not available) & $\begin{array}{l}48.6 \% \text { versus } 17.8 \% \\
p=<0.001\end{array}$ \\
\hline Indini et al [51] & Melanoma & 173 & $\begin{array}{l}\text { Nivolumab or } \\
\text { pembrolizumab }\end{array}$ & $\begin{array}{l}\text { OS (HR: } 0.39 ; 95 \% \mathrm{Cl}: 0.18-0.81 ; p=0.007) \\
\text { PFS (HR 0.47; 95\% Cl 0.26-0.86; } p=.016)\end{array}$ & $\begin{array}{l}\text { ORR (HR: } 1.95 ; 95 \% \mathrm{Cl}: \\
0.91-4.15 ; p<0.082) \\
\text { DCR (HR: } 1.98 ; 95 \% \mathrm{Cl}: \\
1.07-3.67 ; p<0.029)\end{array}$ \\
\hline Baldini et al [78] & NSCLC & 1959 & Nivolumab & $\begin{array}{l}\text { OS: } 16.7 \text { months ( } 95 \% \mathrm{Cl}: 13.5-19.9) \\
\text { versus } 9.4 \text { ( } 95 \% \mathrm{Cl}: 8.4-10.4) ; p<0.00001 \\
\text { PFS: } 6.0 \text { months ( } 95 \% \mathrm{Cl}: 4.9-7.1 \text { ) versus } \\
3.0 \text { ( } 95 \% \mathrm{Cl}: 2.8-3.2) ; p<0.0001\end{array}$ & $\begin{array}{l}\text { RR: } 27.2 \% \text { versus } 15.2 \% \\
p<0.0001 \\
\text { DCR: } 60.5 \% \text { versus } 40.2 \% \text {; } \\
p<0.0001\end{array}$ \\
\hline $\begin{array}{l}\text { Shankar et al } \\
\text { [79] }\end{array}$ & NSCLC & 623 & $\begin{array}{l}\mathrm{ICI} \text { monotherapy or in } \\
\text { combination }\end{array}$ & $\begin{array}{l}\text { OS (HR: } 0.86 ; 95 \% \mathrm{Cl}: 0.66-1.12 ; p=0 \\
.26) \text { and PFS (HR: } 0.68 ; 95 \% \mathrm{Cl}: 0.55- \\
0.85 ; p=0.001)\end{array}$ & Not available \\
\hline $\begin{array}{l}\text { Grangeon et al } \\
{[80]}\end{array}$ & NSCLC & 270 & $\begin{array}{l}\text { Anti-PD-L1 or } \\
\text { anti-PD-1 }\end{array}$ & $\begin{array}{l}\text { OS (HR: 0.29; } 95 \% \mathrm{Cl}: 0.18-0.46 ; p \\
=0.001) \text { and PFS (HR: } 0.42 ; 95 \% \mathrm{Cl}: \\
0.32-0.57 ; p=<0.001)\end{array}$ & $\begin{array}{l}22.9 \% \text { versus } 5.7 \% ; p= \\
<0.0001) \text { and } \mathrm{DCR}(76 \% \\
\text { versus } 58 \% ; p=<0.001)\end{array}$ \\
\hline $\begin{array}{l}\text { Ricciuti et al } \\
\text { [81] }\end{array}$ & NSCLC & 195 & Nivolumab & $\begin{array}{l}\text { OS (HR: } 0.33 ; 95 \% \mathrm{Cl}: 0.23-0.47 ; p \\
<0.001) \text { and PFS (HR: } 0.41 ; 95 \% \mathrm{Cl} \text { : } \\
0.3-0.57 ; p<0.001)\end{array}$ & $\begin{array}{l}\text { ORR (43.5\% versus } 10 \% ; \\
p<0.001) \text { and DCR }(70.5 \% \\
\text { versus } 18.1 \% ; p<0.0001)\end{array}$ \\
\hline
\end{tabular}


Table 2. Studies comparing the association between irAEs and clinical outcomes. (Continued)

\begin{tabular}{|c|c|c|c|c|c|}
\hline Vitale et al [82] & $\mathrm{mRCC}$ & 167 & Nivolumab & $\begin{array}{l}\text { OS ( } 20.1 \text { months; HR: } 0.38 ; 95 \% \mathrm{Cl} \text { : } \\
0.23-0.63) \\
\text { PFS (7.86 months; HR: } 0.44 ; 95 \% \mathrm{Cl} \text { : } \\
0.29-0.66 \text { ) }\end{array}$ & $\begin{array}{l}\text { ORR (27.3\% versus } \\
\text { 13.7\%; OR: } 2.36 ; 95 \% \mathrm{Cl} \text { : } \\
\text { 1.03-5.44) } \\
\text { DCR (68.8\% versus } \\
\text { 48\%; OR: } 2.4 ; 95 \% \mathrm{Cl} \text { : } \\
\text { 1.23-4.67) }\end{array}$ \\
\hline $\begin{array}{l}\text { Verzoni et al } \\
\text { [83] }\end{array}$ & $\mathrm{RCC}$ & 389 & Nivolumab & $\begin{array}{l}\text { OS (HR: } 0.57 ; 95 \% \mathrm{Cl}: 0.35-0.93 \\
p=0.02)\end{array}$ & Not available \\
\hline Maher et al [84] & UC & 1,747 & $\begin{array}{l}\text { Pembrolizumab or } \\
\text { Atezolizumab }\end{array}$ & OS (HR: 0.53; 95\% Cl: 0.43-0.66) & Not available \\
\hline $\begin{array}{l}\text { Morales-Berera } \\
\text { et al [85] }\end{array}$ & UC & 52 & $\mathrm{ICl}$ agents & OS (21.91 versus 6.47 months; $p=0.004$ ) & $\begin{array}{l}\text { DCR (79\% versus } 36.3 \% \\
p=0.002)\end{array}$ \\
\hline Foster et al [67] & HNC & 114 & Anti-PD therapy & $\begin{array}{l}\text { OS (12.5 versus } 6.8 \text { months; } p=0.0007) \\
\text { and PFS ( } 6.9 \text { versus } 2.1 \text { months; } p=0.0004 \text { ) }\end{array}$ & $\begin{array}{l}\text { ORR }(30.6 \% \text { versus } 12.3 \% \\
p=0.02)\end{array}$ \\
\hline Ando et al [86] & Advanced GC & 108 & $\begin{array}{l}\text { Nivolumab or } \\
\text { Pembrolizumab }\end{array}$ & $\begin{array}{l}\text { OS (12.2 months; } 95 \% \mathrm{Cl}=3.8-\mathrm{NA}) \\
\text { versus (3.5 months }(95 \% \mathrm{Cl}: 2.9-5.1 \text { ) } \\
\text { PFS (3.9 months; } 95 \% \mathrm{Cl}=2.8-9.3 \text { ) } \\
\text { versus } 1.8 \text { months }(95 \% \mathrm{Cl}=1.4--2.1 \text { ) }\end{array}$ & $28.5 \%$ versus $3 \%$ \\
\hline $\begin{array}{l}\text { Masuda et al } \\
{[87]}\end{array}$ & GC & 65 & Nivolumab & $\begin{array}{l}\text { OS (HR: } 0.17 ; p<0.001) \text { and PFS } \\
\text { (HR: } 0.11 ; p<0.001)\end{array}$ & Not available \\
\hline Das et al [61] & $\begin{array}{l}\text { Gastrointestinal } \\
\text { tumours }\end{array}$ & 76 & $\begin{array}{l}\mathrm{ICl} \text { monotherapy or in } \\
\text { combination }\end{array}$ & $\begin{array}{l}\text { OS (32.4 versus } 8.5 \text { months; } p=0.0036) \\
\text { PFS (32.4 versus } 4.8 \text { months; } p=0.0001 \text { ) }\end{array}$ & Not available \\
\hline $\begin{array}{l}\text { Riudavets et al } \\
\text { [88] }\end{array}$ & Solid tumours & 178 & $\begin{array}{l}\text { Pembrolizumab, nivolumab } \\
\text { and atezolizumab }\end{array}$ & $\begin{array}{l}\text { OS ( } 37.3 \text { versus } 7.8 \text { months; } p<0.0001) \\
\text { and PFS ( } 7.9 \text { versus } 2.6 \text { months; } p<0.0001 \text { ) }\end{array}$ & Not available \\
\hline $\begin{array}{l}\text { Matsuoka et al } \\
\text { [89] }\end{array}$ & $\begin{array}{l}\text { Across various } \\
\text { tumours }\end{array}$ & 280 & Any ICl agent & OS $(p<0.01)$ and PFS $(p<0.01)$ & $\begin{array}{l}\text { ORR (30.4\% versus } 12.7 \% ; \\
p<0.01)\end{array}$ \\
\hline
\end{tabular}

irAEs, Immune-related adverse events; ICI, Immune checkpoint inhibitors; OS, Overall survival; PFS, Progression-free survival; HR, Hazard ratio; Cl, Confidence interval; ORR, Overall response rate; DCR, Disease control rate; NA, Not applicable; NSCLC, Non-small cell lung cancer; mRCC, Metastatic renal cell carcinoma; UC, Urothelial carcinoma; HNC, Head and neck cancer

There is a need for a global initiative to develop an international registry on the reporting of irAEs with well-curated data to gauge the harm and the benefits of $\mathrm{ICl}$ agents and further understand if there is a clinically meaningful association between toxicities and survival benefits [76]. Also, an enhanced selection criterion to identify patients with advanced-stage cancers who will or will not benefit from $\mathrm{ICl}$ agents is essential, and the need to involve early primary palliative care for the potential non-responders. Patient education and a dedicated multi-disciplinary team are crucial for diagnosing and timely treatment of irAEs [77].

\section{Conclusions and perspectives}

Despite all the controversy in this space, the general consensus is that irAEs are not a pre-requisite for $I C I$ benefit but rather a positive heralding sign of clinical benefit. According to all the studies we reviewed, the association between irAEs and clinical outcomes remains disperse. While the objective response rate and DCR are mostly higher in those who develop irAEs, the OS and PFS data are dependent on the tumour type, degree of toxicities, affected spectrum of system/organs and inherent patient characteristics. 
The development of irAEs appears to be more associated with both PD-1 and PD-L1 response and benefits as compared to anti-CTLA-4. There is a paucity of large well-powered studies to refute or confirm the exact benefit of the occurrence of irAEs during ICI therapy. Several questions remain unanswered, including the association between irAEs onset and the type of organ system toxicities, toxicity grading, ITBs, confounding comorbidities like autoimmune diseases, immune heterogeneity and patient intrinsic factors. Therefore, a harmonised global registry on the incidence of irAEs and their associated clinical outcomes is required to open a new era of immuno-oncology.

\section{Conflicts of interest}

The authors declare that they have no conflicts of interest.

\section{Authors' contributions}

All authors substantially contributed to the conception, drafting and revising of the work and approved the final manuscript. All authors agree to be accountable for all aspects of the work in ensuring the accuracy and integrity of the work.

\section{Funding}

No funding was received for this work.

\section{Disclosures}

None.

\section{References}

1. Ribas A, and Wolchok JD (2018) Cancer immunotherapy using checkpoint blockade Science 359(6382) 1350-1355 https://doi. org/10.1126/science.aar4060 PMID: 29567705 PMCID: 7391259

2. Dobosz P, and Dzieciatkowski T (2019) The intriguing history of cancer immunotherapy Front Immunol 102965 https://doi.org/10.3389/ fimmu.2019.02965

3. Zhang Y, and Zhang Z (2020) The history and advances in cancer immunotherapy: understanding the characteristics of tumor-infiltrating immune cells and their therapeutic implications Cell Mol Immunol 17(8) 807-821 https://doi.org/10.1038/s41423-020-0488-6 PMID: 32612154 PMCID: 7395159

4. Reck M, Rodríguez-Abreu D, and Robinson AG, et al (2016) Pembrolizumab versus chemotherapy for PD-L1-positive non-small-cell lung cancer N Engl J Med 375(19) 1823-1833 https://doi.org/10.1056/NEJMoa1606774 PMID: 27718847

5. Gillison ML, Blumenschein G, Jr., and Fayette J, et al (2018) CheckMate 141: 1-year update and subgroup analysis of nivolumab as first-line therapy in patients with recurrent/metastatic head and neck cancer Oncologist 23(9) 1079-1082 https://doi.org/10.1634/ theoncologist.2017-0674 PMID: 29866947 PMCID: 6221824

6. Larkin J, Chiarion-Sileni V, and Gonzalez R, et al (2015) Combined Nivolumab and Ipilimumab or Monotherapy in Untreated Melanoma N Engl J Med 373(1) 23-34 https://doi.org/10.1056/NEJMoa1504030 PMID: 26027431 PMCID: 5698905 
7. Motzer RJ, Tannir NM, and McDermott DF, et al (2018) Nivolumab plus ipilimumab versus sunitinib in advanced renal-cell carcinoma N Engl J Med 378(14) 1277-1290 https://doi.org/10.1056/NEJMoa1712126 PMID: 29562145 PMCID: 5972549

8. Sharma P, Retz M, and Siefker-Radtke A, et al (2017) Nivolumab in metastatic urothelial carcinoma after platinum therapy (CheckMate 275): a multicentre, single-arm, phase 2 trial Lancet Oncol 18(3) 312-322 https://doi.org/10.1016/S1470-2045(17)30065-7 PMID: 28131785

9. Vaughn DJ, Bellmunt J, and Fradet Y, et al (2018) Health-related quality-of-life analysis from KEYNOTE-045: a phase III study of pembrolizumab versus chemotherapy for previously treated advanced urothelial cancer J Clin Oncol 36(16) 1579-1587 https://doi. org/10.1200/JCO.2017.76.9562 PMID: 29590008

10. Cella D, Grünwald V, and Escudier B, et al (2019) Patient-reported outcomes of patients with advanced renal cell carcinoma treated with nivolumab plus ipilimumab versus sunitinib (CheckMate 214): a randomised, phase 3 trial Lancet Oncol 20(2) 297-310 https://doi. org/10.1016/S1470-2045(18)30778-2 PMID: 30658932 PMCID: 6701190

11. Brahmer JR, Lacchetti C, and Schneider BJ, et al (2018) Management of immune-related adverse events in patients treated with immune checkpoint inhibitor therapy: American society of clinical oncology clinical practice guideline J Clin Oncol 36(17) 1714-1768 https:// doi.org/10.1200/JCO.2017.77.6385 PMID: 29442540 PMCID: 6481621

12. Hasan Ali O, Diem S, and Markert E, et al (2016) Characterization of nivolumab-associated skin reactions in patients with metastatic non-small cell lung cancer Oncoimmunology 5(11) e1231292 https://doi.org/10.1080/2162402X.2016.1231292 PMID: 27999741 PMCID: 5139632

13. Weinmann SC, and Pisetsky DS (2019) Mechanisms of immune-related adverse events during the treatment of cancer with immune checkpoint inhibitors Rheumatology (Oxford) 58(Suppl 7) vii59-vii67 https://doi.org/10.1093/rheumatology/kez308

14. Michot JM, Bigenwald C, and Champiat S, et al (2016) Immune-related adverse events with immune checkpoint blockade: a comprehensive review Eur J Cancer 54 139-148 https://doi.org/10.1016/j.ejca.2015.11.016 PMID: 26765102

15. Nishijima TF, Shachar SS, and Nyrop KA, et al (2017) Safety and tolerability of PD-1/PD-L1 inhibitors compared with chemotherapy in patients with advanced cancer: a meta-analysis Oncologist 22(4) 470-479 https://doi.org/10.1634/theoncologist.2016-0419 PMID: 28275115 PMCID: 5388381

16. Raschi E, Gatti M, and Gelsomino F, et al (2020) Lessons to be learnt from real-world studies on immune-related adverse events with checkpoint inhibitors: a clinical perspective from pharmacovigilance Target Oncol 15(4) 449-466 https://doi.org/10.1007/s11523-02000738-6 PMID: 32725437 PMCID: 7434791

17. Raschi E, Mazzarella A, and Antonazzo IC, et al (2019) Toxicities with immune checkpoint inhibitors: emerging priorities from disproportionality analysis of the FDA adverse event reporting system Target Oncol 14(2) 205-221 https://doi.org/10.1007/s11523-01900632-w PMID: 30927173

18. Fujii T, Naing A, and Rolfo C, et al (2018) Biomarkers of response to immune checkpoint blockade in cancer treatment Crit Rev Oncol Hematol 130 108-120 https://doi.org/10.1016/j.critrevonc.2018.07.010 PMID: 30196907

19. Hua C, Boussemart L, and Mateus C, et al Association of vitiligo with tumor response in patients with metastatic melanoma treated with pembrolizumab JAMA Dermatol 152(1) 45-51 PMID: 26501224

20. Maillet D, Corbaux P, and Stelmes JJ, et al (2020) Association between immune-related adverse events and long-term survival outcomes in patients treated with immune checkpoint inhibitors Eur J Cancer 132 61-70 https://doi.org/10.1016/j.ejca.2020.03.017 PMID: 32334337

21. Martins F, Sofiya L, and Sykiotis GP, et al (2019) Adverse effects of immune-checkpoint inhibitors: epidemiology, management and surveillance Nat Rev Clin Oncol 16(9) 563-580 https://doi.org/10.1038/s41571-019-0218-0 PMID: 31092901 
22. Toi Y, Sugawara S, and Kawashima Y, et al (2018) Association of immune-related adverse events with clinical benefit in patients with advanced non-small-cell lung cancer treated with nivolumab Oncologist 23(11) 1358-1365 https://doi.org/10.1634/theoncologist.2017-0384 PMID: 29934411 PMCID: 6291330

23. Gleiss A, Oberbauer R, and Heinze G (2018) An unjustified benefit: immortal time bias in the analysis of time-dependent events Transpl Int 31(2) 125-130 https://doi.org/10.1111/tri.13081

24. Dall'Olio FG, Rizzo A, and Mollica V, et al (2021) Immortal time bias in the association between toxicity and response for immune checkpoint inhibitors: a meta-analysis Immunotherapy 13(3) 257-270 https://doi.org/10.2217/imt-2020-0179

25. Sibaud V (2018) Dermatologic ractions to immune checkpoint inhibitors: skin toxicities and immunotherapy Am J Clin Dermatol 19(3) 345-361 https://doi.org/10.1007/s40257-017-0336-3

26. NCCN Guidelines (2020) Management of Immunotherapy-Related Toxicities Version 1 (NCCN) Date accessed: 16/12/19

27. Das S, and Johnson DB (2019) Immune-related adverse events and anti-tumor efficacy of immune checkpoint inhibitors J Immunother Cancer 7(1) 306 https://doi.org/10.1186/s40425-019-0805-8 PMID: 31730012 PMCID: 6858629

28. Pickwell-Smith BA, So AC, and Board RE (2018) Managing side effects of cancer immunotherapy for the acute physician Br J Hosp Med (Lond) 79(7) 372-327 https://doi.org/10.12968/hmed.2018.79.7.372

29. Johnson DB, Balko JM, and Compton ML, et al (2016) Fulminant myocarditis with combination immune checkpoint blockade $\mathrm{N}$ Engl J Med 375(18) 1749-1755 https://doi.org/10.1056/NEJMoa1609214 PMID: 27806233 PMCID: 5247797

30. Wang DY, Salem JE, and Cohen JV, et al (2018) Fatal toxic effects associated with immune checkpoint inhibitors: a systematic review and meta-analysis JAMA Oncol 4(12) 1721-1728 https://doi.org/10.1001/jamaoncol.2018.3923 PMID: 30242316 PMCID: 6440712

31. Abu-Sbeih H, Ali FS, and Qiao W, et al (2019) Immune checkpoint inhibitor-induced colitis as a predictor of survival in metastatic melanoma Cancer Immunol Immunother 68(4) 553-561 https://doi.org/10.1007/s00262-019-02303-1 PMID: 30666357

32. Owen DH, Wei L, and Bertino EM, et al (2018) Incidence, risk factors, and effect on survival of immune-related adverse events in patients with non-small-cell lung cancer Clin Lung Cancer 19(6) e893-e900 https://doi.org/10.1016/j.cllc.2018.08.008 PMID: 30197259 PMCID: 7193681

33. Wang Y, Zhou S, and Yang F, et al (2019) Treatment-related adverse events of PD-1 and PD-L1 inhibitors in clinical trials: a systematic review and meta-analysis JAMA Oncol 5(7) 1008-1019 https://doi.org/10.1001/jamaoncol.2019.0393 PMID: 31021376 PMCID: 6487913

34. Arnaud-Coffin P, Maillet D, and Gan HK, et al (2019) A systematic review of adverse events in randomized trials assessing immune checkpoint inhibitors Int J Cancer 145(3) 639-648 https://doi.org/10.1002/ijc.32132 PMID: 30653255

35. Da L, Teng $\mathrm{Y}$, and Wang N, et al (2019) Organ-specific immune-related adverse events associated with immune checkpoint inhibitor monotherapy versus combination therapy in cancer: a meta-analysis of randomized controlled trials Front Pharmacol 101671 https:// doi.org/10.3389/fphar.2019.01671

36. Park R, Lopes L, and Cristancho CR, et al (2020) Treatment-related adverse events of combination immune checkpoint inhibitors: systematic review and meta-analysis Front Oncol 10258 https://doi.org/10.3389/fonc.2020.00258 PMID: 32257944 PMCID: 7090167

37. Abou Alaiwi S, Xie W, and Nassar AH, et al (2020) Safety and efficacy of restarting immune checkpoint inhibitors after clinically significant immune-related adverse events in metastatic renal cell carcinoma J Immunother Cancer 8(1) e000144 https://doi.org/10.1136/ jitc-2019-000144 PMID: 32066646 PMCID: 7057439

38. Pollack MH, Betof A, and Dearden H, et al (2018) Safety of resuming anti-PD-1 in patients with immune-related adverse events (irAEs) during combined anti-CTLA-4 and anti-PD1 in metastatic melanoma Ann Oncol 29(1) 250-255 https://doi.org/10.1093/annonc/ $\underline{\text { mdx642 PMCID: } 5834131}$ 
39. Barroso-Sousa R, Barry WT, and Garrido-Castro AC, et al (2018) Incidence of endocrine dysfunction following the use of different immune checkpoint inhibitor regimens: a systematic review and meta-analysis JAMA Oncol 4(2) 173-182 https://doi.org/10.1001/ jamaoncol.2017.3064 PMCID: $\underline{5838579}$

40. Shoushtari AN, Friedman CF, and Navid-Azarbaijani P, et al (2018) Measuring toxic effects and time to treatment failure for nivolumab plus ipilimumab in melanoma JAMA Oncol 4(1) 98-101 https://doi.org/10.1001/jamaoncol.2017.2391 PMCID: 5833656

41. Weber JS, Hodi FS, and Wolchok JD, et al (2017) Safety profile of nivolumab monotherapy: a pooled analysis of patients with advanced melanoma J Clin Oncol 35(7) 785-792 https://doi.org/10.1200/JCO.2015.66.1389 PMID: 28068177

42. Xu C, Chen YP, and Du XJ, et al (2018) Comparative safety of immune checkpoint inhibitors in cancer: systematic review and network meta-analysis BMJ 363 k4226 https://doi.org/10.1136/bmj.k4226 PMID: 30409774 PMCID: 6222274

43. Khoja L, Day D, and Wei-Wu Chen T, et al (2017) Tumour- and class-specific patterns of immune-related adverse events of immune checkpoint inhibitors: a systematic review Annals of Oncology 28(10) 2377-2385 https://doi.org/10.1093/annonc/mdx286 PMID: 28945858

44. Berner F, Bomze D, Diem S, and Ali OH, et al (2019) Association of checkpoint inhibitor-induced toxic effects with shared cancer and tissue antigens in non-small cell lung cancer JAMA Oncol 5(7) 1043-1047 https://doi.org/10.1001/jamaoncol.2019.0402 PMID: 31021392 PMCID: 6487908

45. Cortellini A, Chiari R, and Ricciuti B, et al (2019) Correlations between the immune-related adverse events spectrum and efficacy of anti-PD1 immunotherapy in NSCLC patients Clin Lung Cancer 20(4) 237 e1-247 e1 https://doi.org/10.1016/j.cllc.2019.02.006 PMID: 30885550

46. Abola MV, Prasad V, and Jena AB (2014) Association between treatment toxicity and outcomes in oncology clinical trials Ann Oncol 25(11) 2284-2289 https://doi.org/10.1093/annonc/mdu444 PMID: 25193993 PMCID: 4207731

47. Cortellini A, Buti S, and Agostinelli V, et al (2019) A systematic review on the emerging association between the occurrence of immunerelated adverse events and clinical outcomes with checkpoint inhibitors in advanced cancer patients Semin Oncol 46(4-5) 362-371 https://doi.org/10.1053/j.seminoncol.2019.10.003 PMID: 31727344

48. Petrelli F, Signorelli D, and Ghidini M, et al (2020) Association of steroids use with survival in patients treated with immune checkpoint inhibitors: a systematic review and meta-analysis Cancers (Basel) 12(3) 546 https://doi.org/10.3390/cancers12030546

49. Kelly K, Manitz J, and Patel MR, et al (2020) Efficacy and immune-related adverse event associations in avelumab-treated patients J Immunother Cancer 8(2) https://doi.org/10.1136/jitc-2020-001427 PMID: 33219092 PMCID: 7682456

50. Naqash AR, Ricciuti B, and Owen DH, et al (2020) Outcomes associated with immune-related adverse events in metastatic nonsmall cell lung cancer treated with nivolumab: a pooled exploratory analysis from a global cohort Cancer Immunol Immunother 69(7) 1177-1187 https://doi.org/10.1007/s00262-020-02536-5 PMID: 32140762

51. Indini A, Di Guardo L, and Cimminiello C, et al (2019) Immune-related adverse events correlate with improved survival in patients undergoing anti-PD1 immunotherapy for metastatic melanoma J Cancer Res Clin Oncol 145(2) 511-221 https://doi.org/10.1007/ s00432-018-2819-x

52. Hussaini S, Chehade R, and Boldt RG, et al (2021) Association between immune-related side effects and efficacy and benefit of immune checkpoint inhibitors - a systematic review and meta-analysis Cancer Treat Rev 92102134 https://doi.org/10.1016/j.ctrv.2020.102134

53. Zhao JJ, Wen XZ, and Ding Y, et al (2020) Association between immune-related adverse events and efficacy of PD-1 inhibitors in Chinese patients with advanced melanoma Aging (Albany NY) 12(11) 10663-10675 https://doi.org/10.18632/aging.103285

54. Yamauchi I, Yasoda A, and Matsumoto S, et al (2019) Incidence, features, and prognosis of immune-related adverse events involving the thyroid gland induced by nivolumab PLoS One 14(5) e0216954 https://doi.org/10.1371/journal.pone.0216954 PMID: 31086392 PMCID: $\underline{6516638}$ 
55. Shimozaki K, Sukawa Y, and Beppu N, et al (2020) Multiple immune-related adverse events and anti-tumor efficacy: real-world data on various solid tumors Cancer Manag Res 12 4585-4593 https://doi.org/10.2147/CMAR.S247554 PMID: 32606951 PMCID: 7305832

56. Zhou X, Yao Z, and Yang H, et al (2020) Are immune-related adverse events associated with the efficacy of immune checkpoint inhibitors in patients with cancer? A systematic review and meta-analysis BMC Med 18(1) 87 https://doi.org/10.1186/s12916-020-01549-2 PMID: 32306958 PMCID: 7169020

57. Aso M, Toi Y, and Sugisaka J, et al (2020) Association between skin reaction and clinical benefit in patients treated with anti-programmed cell death 1 monotherapy for advanced non-small cell lung cancer Oncologist 25(3) e536-e544 https://doi.org/10.1634/ theoncologist.2019-0550 PMID: 32162801 PMCID: 7066688

58. Kostine M, Rouxel L, and Barnetche T, et al (2018) Rheumatic disorders associated with immune checkpoint inhibitors in patients with cancer-clinical aspects and relationship with tumour response: a single-centre prospective cohort study Ann Rheum Dis 77(3) 393-398 https://doi.org/10.1136/annrheumdis-2017-212257

59. Zhang M, Rodrigues AJ, and Pollom EL, et al (2021) Improved survival and disease control following pembrolizumab-induced immunerelated adverse events in high PD-L1 expressing non-small cell lung cancer with brain metastases J Neurooncol 152 125-134 https:// doi.org/10.1007/s11060-020-03686-3 PMID: 33415659 PMCID: 8214448

60. Barrón F, Sánchez R, and Arroyo-Hernández M, et al (2020) Risk of developing checkpoint immune pneumonitis and its effect on overall survival in non-small cell lung cancer patients previously treated with radiotherapy Front Oncol 10570233 https://doi.org/10.3389/ fonc.2020.570233 PMID: 33117699 PMCID: 7550759

61. Das S, Ciombor KK, and Haraldsdottir S, et al (2020) Immune-related adverse events and immune checkpoint inhibitor efficacy in patients with gastrointestinal cancer with Food and Drug Administration-approved indications for immunotherapy Oncologist 25(8) 669-679 https://doi.org/10.1634/theoncologist.2019-0637 PMID: 31943525 PMCID: 7418359

62. Kijima T, Fukushima H, and Kusuhara S, et al (2020) Association between the occurrence and spectrum of immune-related adverse events and efficacy of pembrolizumab in asian patients with advanced urothelial cancer: multicenter retrospective analyses and systematic literature review Clin Genitourin Cancer 19 208-216 https://doi.org/10.1016/j.clgc.2020.07.003 PMID: 32800718

63. Shabto JM, Martini DJ, and Liu Y, et al (2019) Association between immune-related adverse events (irAEs) and clinical outcomes (CO) in advanced urothelial cancer patients (pts) treated with immunotherapy (IO) J Clin Oncol 37(7_suppl) 472 https://doi.org/10.1200/ JCO.2019.37.7_suppl.472

64. Elias R, Yan F, and Singla N, et al (2019) Immune-related adverse events are associated with improved outcomes in ICl-treated renal cell carcinoma patients J Clin Oncol 37(7_suppl) 645 https://doi.org/10.1200/JCO.2019.37.7_suppl.645

65. Ishihara H, Takagi T, and Kondo T, et al (2019) Association between immune-related adverse events and prognosis in patients with metastatic renal cell carcinoma treated with nivolumab Urol Oncol 37(6) 355e21-355e29 https://doi.org/10.1016/j.urolonc.2019.03.003

66. Burtness B, Harrington KJ, and Greil R, et al (2019) Pembrolizumab alone or with chemotherapy versus cetuximab with chemotherapy for recurrent or metastatic squamous cell carcinoma of the head and neck (KEYNOTE-048): a randomised, open-label, phase 3 study Lancet 394(10212) 1915-1928 https://doi.org/10.1016/S0140-6736(19)32591-7 PMID: 31679945

67. Foster CC, Kochanny S, and Khattri A, et al (2018) Association of immune-related adverse events (irAEs) with improved response, progression-free survival, and overall survival for patients with metastatic head and neck cancer receiving anti-PD-1 therapy J Clin Oncol 36(15_suppl) 6014 https://doi.org/10.1200/JCO.2018.36.15_suppl.6014

68. Economopoulou P, Kotsantis I, and Papaxoinis G, et al (2020) Association of autoimmunity with survival in patients with recurrent/metastatic head and neck squamous cell carcinoma treated with nivolumab Oral Oncol 111105013 https://doi.org/10.1016/j.oraloncology.2020.105013 PMID: 32977184 
69. Teraoka S, Fujimoto D, and Morimoto T, et al (2017) Early immune-related adverse events and association with outcome in advanced non-small cell lung cancer patients treated with nivolumab: a prospective cohort study J Thorac Oncol 12(12) 1798-1805 https://doi. org/10.1016/j.jtho.2017.08.022 PMID: 28939128

70. Boudewijns S, Westdorp $\mathrm{H}$, and Koornstra $\mathrm{RH}$, et al (2016) Immune-related adverse events of dendritic cell vaccination correlate with immunologic and clinical outcome in stage III and IV melanoma patients J Immunother 39(6) 241-248 https://doi.org/10.1097/ CJI.0000000000000127 PMID: 27227325 PMCID: 4902323

71. Riudavets M, Mosquera J, and Garcia-Campelo R, et al (2020) Immune-related adverse events and corticosteroid use for cancer-related symptoms are associated with efficacy in patients with non-small cell lung cancer receiving anti-PD-(L)1 blockade agents Front Oncol 10 1677

72. Shafqat $H$, Gourdin $T$, and Sion A (2018) Immune-related adverse events are linked with improved progression-free survival in patients receiving anti-PD-1/PD-L1 therapy Semin Oncol 45(3) 156-163 https://doi.org/10.1053/j.seminoncol.2018.07.003 PMID: 30348532

73. Ouwerkerk W, van den Berg M, and van der Niet S, et al (2019) Biomarkers, measured during therapy, for response of melanoma patients to immune checkpoint inhibitors: a systematic review Melanoma Res 29(5) 453-464 https://doi.org/10.1097/CMR.0000000000000589 PMID: 30855527 PMCID: 6727956

74. Giobbie-Hurder A, Gelber RD, and Regan MM (2013) Challenges of guarantee-time bias J Clin Oncol 31(23) 2963-2969 https://doi. org/10.1200/JCO.2013.49.5283 PMID: 23835712 PMCID: 3732313

75. Dall'Olio FG, Rizzo A, and Mollica V, et al (2021) Immortal time bias in the association between toxicity and response for immune checkpoint inhibitors: a meta-analysis Immunotherapy 13(3):257-270 https://doi.org/10.2217/imt-2020-0179

76. Heinzerling L, Ascierto PA, and Dummer R, et al (2019) Adverse events 2.0-Let us get SERIOs: new reporting for adverse event outcomes needed in the era of immunooncology Eur J Cancer 112 29-31 https://doi.org/10.1016/j.ejca.2019.01.015 PMID: 30903870

77. Bascioni R and Giorgi F (2015) Waiting for an answer: hospice care and novel immunotherapy J Palliat Med 18(12) 1080-1081 https:// doi.org/10.1089/jpm.2015.0301 PMID: 26554865

78. Baldini E, Lunghi A, and Cortesi E, et al (2020) Immune-related adverse events correlate with clinical outcomes in NSCLC patients treated with nivolumab: the Italian NSCLC expanded access program Lung Cancer 140 59-64 https://doi.org/10.1016/j.lungcan.2019.12.014

79. Shankar B, Zhang J, and Naqash AR, F et al (2020) Multisystem immune-related adverse events associated with immune checkpoint inhibitors for treatment of non-small cell lung cancer JAMA Oncol 6(12) 1952-1956 https://doi.org/10.1001/jamaoncol.2020.5012 PMID: 33119034 PMCID: 7596677

80. Grangeon M, Tomasini P, and Chaleat S, et al (2019) Association between immune-related adverse events and efficacy of immune checkpoint inhibitors in non-small-cell lung cancer Clin Lung Cancer 20(3) 201-207

81. Ricciuti B, Genova C, and De Giglio A, et al (2019) Impact of immune-related adverse events on survival in patients with advanced nonsmall cell lung cancer treated with nivolumab: long-term outcomes from a multi-institutional analysis J Cancer Res Clin Oncol 145(2) 479-485 https://doi.org/10.1007/s00432-018-2805-3

82. Vitale MG, Pipitone S, and Venturelli M, et al (2020) Correlation between immune-related adverse event (IRAE) occurrence and clinical outcome in patients with metastatic renal cell carcinoma (mRCC) treated with nivolumab: Iraene trial, an Italian multi-institutional retrospective study Clin Genitourin Cancer 18(6) 477-488 https://doi.org/10.1016/j.clgc.2020.05.010 PMID: 32732112

83. Verzoni E, Cartenì G, and Cortesi E, et al (2019) Real-world efficacy and safety of nivolumab in previously-treated metastatic renal cell carcinoma, and association between immune-related adverse events and survival: the Italian expanded access program $J$ Immunother Cancer 7(1) 99 https://doi.org/10.1186/s40425-019-0579-z PMID: 30944023 PMCID: 6448290 
84. Maher VE, Fernandes LL, and Weinstock C, et al (2019) Analysis of the association between adverse events and outcome in patients receiving a programmed death protein 1 or programmed death ligand 1 antibody J Clin Oncol 37(30) 2730-2737 https://doi.org/10.1200/ JCO.19.00318 PMID: 31116675

85. Morales-Barrera R, Rodriguez CS, and Gonzalez M, et al (2019) Impact of immune-related adverse events on survival in patients with metastastic urothelial carcinoma treated with immune-checkpoint inhibitors J Clin Oncol 37(15_suppl) 4531 https://doi.org/10.1200/ JCO.2019.37.15_suppl.4531

86. Ando T, Ueda A, and Ogawa K, et al (2021) Prognosis of immune-related adverse events in patients with advanced gastric cancer treated with nivolumab or pembrolizumab: a multicenter retrospective analysis In Vivo 35(1) 475-482 https://doi.org/10.21873/invivo.12281 PMID: 33402499 PMCID: 7880732

87. Masuda K, Shoji H, and Nagashima K, et al (2019) Correlation between immune-related adverse events and prognosis in patients with gastric cancer treated with nivolumab BMC Cancer 19(1) 974 https://doi.org/10.1186/s12885-019-6150-y PMID: 31638948 PMCID: 6805586

88. Riudavets M, Barba A, and Maroto P, et al (2018) Correlation between immune-related adverse events (irAEs) and efficacy in patients with solid tumors treated with immune-checkpoints inhibitors (ICls) J Clin Oncol 36(15_suppl) 3064 https://doi.org/10.1200/ JCO.2018.36.15_suppl.3064

89. Matsuoka H, Hayashi T, and Takigami K, et al (2020) Correlation between immune-related adverse events and prognosis in patients with various cancers treated with anti PD-1 antibody BMC Cancer 20(1) 656 https://doi.org/10.1186/s12885-020-07142-3 PMID: 32664888 PMCID: 7362440 